\title{
Comparative epidemiology of chronic fatigue syndrome in Brazilian and British primary care: prevalence and recognition
}

\author{
Hyong Jin Cho, Paulo Rossi Menezes, Matthew Hotopf, Dinesh Bhugra and Simon Wessely
}

\section{Background}

Although fatigue is a ubiquitous symptom across countries, clinical descriptions of chronic fatigue syndrome have arisen from a limited number of high-income countries. This might reflect differences in true prevalence or clinical recognition influenced by sociocultural factors.

\section{Aims \\ To compare the prevalence, physician recognition and diagnosis of chronic fatigue syndrome in London and São} Paulo.

\section{Method}

Primary care patients in London $(n=2459)$ and São Paulo ( $n=3914)$ were surveyed for the prevalence of chronic fatigue syndrome. Medical records were reviewed for the physician recognition and diagnosis.

\section{Results}

The prevalence of chronic fatigue syndrome according to Centers for Disease Control 1994 criteria was comparable in Britain and Brazil: $2.1 \%$ v. $1.6 \%(P=0.20)$. Medical records review identified 11 diagnosed cases of chronic fatigue syndrome in Britain, but none in Brazil $(P<0.001)$.

\section{Conclusions}

The primary care prevalence of chronic fatigue syndrome was similar in two culturally and economically distinct nations. However, doctors are unlikely to recognise and label chronic fatigue syndrome as a discrete disorder in Brazil. The recognition of this illness rather than the illness itself may be culturally induced.

\section{Declaration of interest}

None. Funding detailed in Acknowledgements.
Fatigue is a ubiquitous symptom in every country so far studied, as shown by high prevalences of fatigue in community and primary care. ${ }^{1-6}$ Studies have also reported fatigue to be one of the most frequent presenting complaints to doctors in primary care. ${ }^{7,8}$ However, clinical descriptions of chronic fatigue syndrome, also known in some countries as myalgic encephalomyelitis, have arisen from a limited number of high-income countries in Northern Europe, North America and Oceania, which might indicate sociocultural influences on the expression of the disorder. ${ }^{9,10}$ Alternatively, it has been suggested that the recognition of the disorder rather than the disorder itself is culturally influenced. ${ }^{11}$ However, to date, no direct comparison of the prevalence and/ or recognition of chronic fatigue syndrome across culturally and economically distinct countries has been conducted. There are very few epidemiological studies of chronic fatigue syndrome in low- and middle-income countries, ${ }^{6}$ where both the population and healthcare professionals seem unfamiliar with the construct of the syndrome. ${ }^{12}$ Furthermore, the prevalence of the syndrome varies widely according to the case definition, method and setting adopted in each study, making comparisons of existing studies unreliable. Indeed, the reported prevalence of chronic fatigue syndrome ranges from $0.004 \%$ to $2.54 \%$ in the community, ${ }^{6,13-20}$ and from $0.11 \%$ to $2.6 \%$ in primary care. ${ }^{5,21-24}$ Our study is a direct comparison of the prevalence and the physician recognition of chronic fatigue syndrome in Brazilian and British primary care using the same method. The prevalence of unexplained chronic fatigue, a less severe 'sub-syndromal' counterpart of chronic fatigue syndrome, was also compared. We hypothesised that the prevalence of unexplained chronic fatigue and chronic fatigue syndrome measured using standardised assessments would be similar in the two primary care settings, but Brazilian general practitioners (GPs) would be less likely to recognise and diagnose chronic fatigue syndrome than their British colleagues.

\section{Method}

\section{Study setting and participants}

The study population consisted of consecutive primary care attenders, aged 18-45 years. The age range was deliberately restricted in an attempt to reduce the likelihood of misdiagnosing medically explained fatigue as unexplained because medical disorders that cause fatigue, for example anaemia, diabetes mellitus and hypothyroidism, are much more prevalent in older age groups. ${ }^{25}$ We deliberately chose to oversample Brazilian patients compared with UK ones in a ratio of 2:1. There are already several prevalence studies on unexplained chronic fatigue/chronic fatigue syndrome in British primary care, ${ }^{23,26,27}$ but none in Brazil. Therefore, a reasonably large sample size was required in Brazil to provide more accurate data on the prevalence of both. Eleven general practices in São Paulo and five in London were selected.

In the UK, primary care is generally the first port of call for the general population when they have a health problem, but Brazilian primary care is more complex. According to the 2000 national census, $24.5 \%$ of the Brazilian population are covered by at least one type of health insurance and the rest dependent on public healthcare. Hence, in order to obtain a study population constituted by different socio-economic groups, reasonably representative of the healthcare seeking population, ten public clinics and one private clinic were selected across São Paulo, and $25.4 \%$ of the Brazilian sample was recruited from the private clinic. In London, four practices were selected from 
inner-city areas and one from a suburban area. Additionally, to maximise the comparability between the two countries, only the public clinics with the Family Health Program, an official programme which resembles the UK system, were recruited in Brazil.

\section{Assessments and procedures}

Fatigue status including severity and duration was assessed with the Chalder Fatigue Questionnaire (CFQ), an 11-item questionnaire widely used to measure physical and mental fatigue. ${ }^{28}$ Prior to this study, we had conducted a rigorous process of translation, back-translation, cross-cultural adaptation and validation of the CFQ in Brazil, the details of which are provided elsewhere. ${ }^{29}$ Based on the validation studies, we used a cut-off of $3 / 4$ by bimodal scoring for substantial fatigue in both countries. ${ }^{28,29}$ Chronic fatigue was defined as a score of four or more on the CFQ with a reported duration of 6 months or greater. Unexplained chronic fatigue was defined as medically unexplained substantial fatigue lasting 6 months or more according to the CFQ and the medical examination. Chronic fatigue syndrome, characterised by severe physical and mental fatigue and other accompanying symptoms which cannot be explained by any other medical condition and have persisted for at least 6 months, was assessed using the Center for Disease Control (CDC) 1994 case definition. ${ }^{30}$ We also determined whether those participants who fulfilled criteria for chronic fatigue had been diagnosed as a case of chronic fatigue syndrome by their GPs. For this purpose, we reviewed their medical records in search for the following diagnostic labels: 'chronic fatigue', 'chronic fatigue syndrome', 'myalgic encephalomyelitis' and 'post-viral fatigue syndrome'. Finally, the 12-item General Health Questionnaire $(\mathrm{GHQ}-12)^{31}$ was used with the conventional cut-off of $3 / 4$ by bimodal scoring to determine probable common mental disorder, as validated in both British ${ }^{31}$ and Brazilian primary care. ${ }^{32}$ Ethical approval was obtained from the research ethics committees of King's College Hospital, Institute of Psychiatry, London, UK, and the Municipal Department of Health of São Paulo and University of São Paulo Medical School, Brazil.

\section{Phase 1 (screening)}

Consecutive attenders at the general practices were invited to participate in the study while they were waiting for their appointment. After reading an information leaflet and signing a consent form, individuals completed the CFQ and the GHQ-12. The questionnaires were read out to illiterate and functionally illiterate participants.

\section{Phase 2}

Those who fulfilled criteria for chronic fatigue were then asked to complete a questionnaire on the CDC-1994 case definition of chronic fatigue syndrome. ${ }^{30}$ Their medical records were reviewed to determine whether they had medical and/or psychiatric exclusionary conditions for the syndrome according to the CDC-1994 case definition, and whether their GPs had diagnosed them as chronic fatigue syndrome cases. The medical records review took place approximately 4 months after the completion of the questionnaire to enable the necessary investigations to be processed. In addition to those investigations requested by the treating doctor, we performed some routine laboratory investigations (liver and thyroid function, full blood count, creatinine and glycosilated haemoglobin) in all Brazilian participants with chronic fatigue because, in Brazil, we expected medical exclusion diagnoses to be more frequent and these investigations were less likely to be requested by the examining doctor. Those individuals with chronic fatigue with neither medical nor psychiatric exclusionary diagnoses for chronic fatigue syndrome were classified as having unexplained chronic fatigue, which therefore corresponds closely to the general concept of medically unexplained symptoms.

\section{Analysis}

Stata Version 10 for Windows ${ }^{33}$ was employed for all statistical analyses and the significance level was set at $P=0.05$. Participant characteristics were compared between the two countries by two-tailed chi-squared or $t$-tests. The prevalence of unexplained chronic fatigue and chronic fatigue syndrome in each country was estimated with the appropriate 95\% confidence interval (CI). The aforementioned diagnostic labels were counted during the medical records review, and the percentage frequency in each country with $95 \%$ CI was calculated as a proxy for the physician recognition rate of the syndrome. The prevalence of each fatigue category - unexplained chronic fatigue, chronic fatigue syndrome and diagnostic labels - was compared between Brazil and the UK using a chi-squared test. Furthermore, in order to take into account the confounding effect of socio-demographic characteristics and common mental disorder, multivariable logistic regression was conducted with country membership (Brazil $v$. $\mathrm{UK}$ ) as the exposure variable and each fatigue category as the outcome variable.

\section{Results}

Valid screening questionnaires were obtained from 3921 participants in São Paulo and 2530 in London (Fig. 1). Seven questionnaires had missing data in Brazil and 71 in the UK. Therefore, 3914 participants were considered for data analysis in Brazil and 2459 in the UK. In Brazil, 1542 (39.4\%) had a score above the cut-off of the CFQ, which corresponds to substantial fatigue, and $609(15.6 \%)$ were individuals with chronic fatigue. In the UK, $1046(42.5 \%)$ had a score above the cut-off and $305(12.4 \%)$ were individuals with chronic fatigue. All sociodemographic characteristics except age were significantly different between the two samples (Table 1). Brazilian participants had a lower education level, and were more likely to be female, to have a stable partner (i.e. married or cohabiting), to have a manual occupation and to be unemployed. Although Brazilian and British participants reported similar fatigue levels, the former group appeared more psychologically distressed as shown by a higher prevalence of common mental disorder (Table 1).

Of the 609 Brazilian and 305 British participants with chronic fatigue, $133(21.8 \%)$ and $52(17.1 \%)$ respectively had a medical or psychiatric exclusionary condition and were classified as individuals with explained chronic fatigue. Consequently, the prevalence of unexplained chronic fatigue was $12.2 \%$ (95\% CI 11.2-13.2) in Brazil and $10.3 \%$ (95\% CI 9.1-11.6) in the UK (Table 2). Thirtysix of 609 Brazilian participants with chronic fatigue (5.9\%) and 99 of 305 British ones (32.5\%) did not supply adequate information for the diagnosis of chronic fatigue syndrome, and they scored slightly lower on the CFQ compared with those who supplied adequate information ( $P=0.05$ in both countries). The prevalence of chronic fatigue syndrome was therefore adjusted for non-response, using non-responders' CFQ score as the predictor of their chronic fatigue syndrome caseness in logistic regression. The estimated prevalence of the syndrome according to the CDC-1994 criteria was $1.6 \%$ (95\% CI 1.3-2.1) in Brazil and $2.1 \%(95 \%$ CI $1.5-2.7)$ in the UK. When controlled for socio-demographic characteristics (age, gender, education, marital 

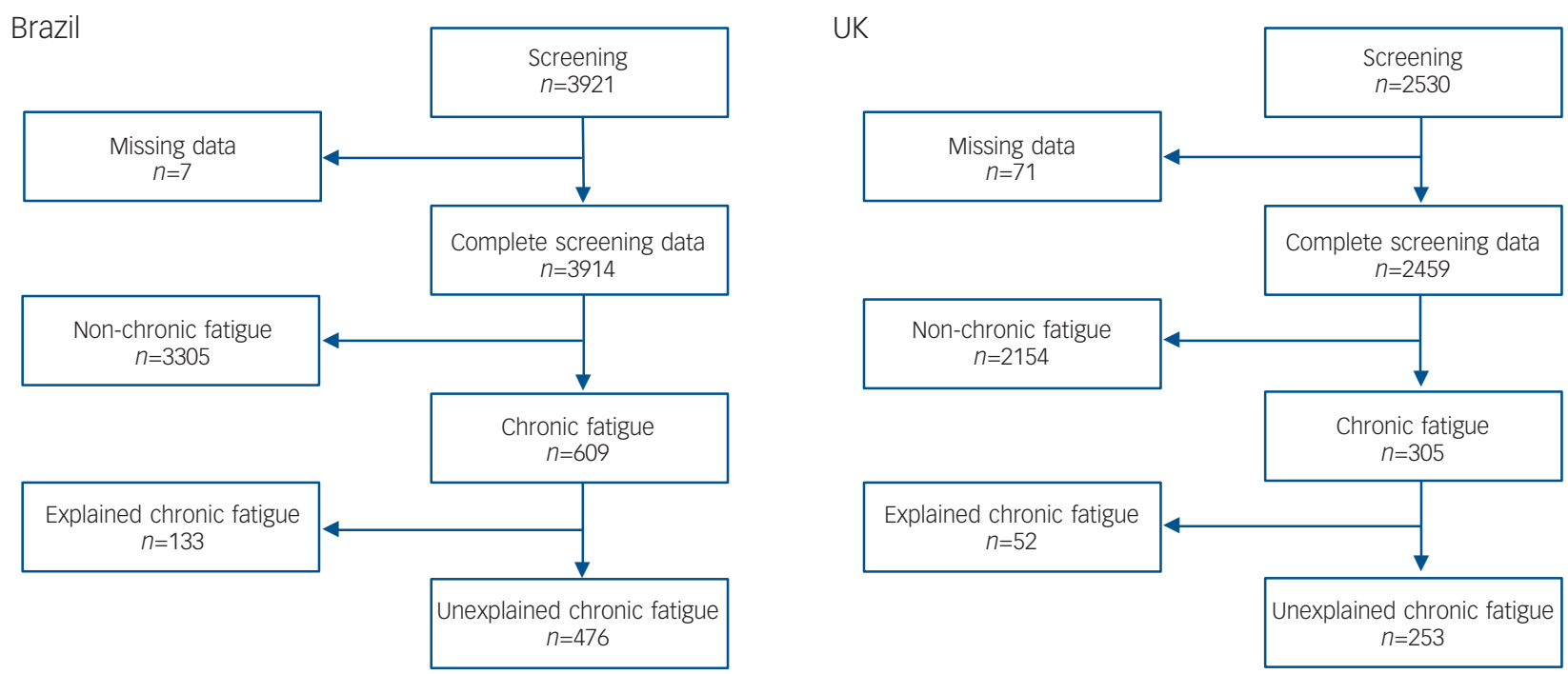

Fig. 1 Flow chart of the study.

\begin{tabular}{|c|c|c|c|}
\hline Variable & Brazil & UK & $P$ \\
\hline Age, years: mean (s.d.) & $31.7(7.9)$ & $31.6(7.2)$ & 0.56 \\
\hline Female, $n(\%)$ & $3120(79.7)$ & $1759(71.5)$ & $<0.001$ \\
\hline Education, years: mean (s.d.) & $8.7(4.4)$ & $15.3(4.5)$ & $<0.001$ \\
\hline Marital status, $n(\%)$ & & & $<0.001$ \\
\hline Married or cohabiting & $2188(55.9)$ & 1304 (53.0) & \\
\hline Single & $1366(34.9)$ & $986(40.1)$ & \\
\hline Separated, divorced or widowed & $360(9.2)$ & $169(6.9)$ & \\
\hline Employment status, $n$ (\%) & & & $<0.001$ \\
\hline Employed & $2645(67.6)$ & $1683(68.4)$ & \\
\hline Student & $206(5.3)$ & $200(8.1)$ & \\
\hline Homemaker & $535(13.7)$ & $316(12.9)$ & \\
\hline Unemployed & $444(11.3)$ & $159(6.5)$ & \\
\hline On sick leave & $84(2.1)$ & $101(4.1)$ & \\
\hline Occupation, $n$ (\%) & & & $<0.001$ \\
\hline Non-manual & $1519(38.8)$ & 1495 (62.1) & \\
\hline Manual & $2092(53.4)$ & 585 (24.3) & \\
\hline Student or never worked & $105(2.7)$ & $185(7.7)$ & \\
\hline Homemaker & $198(5.1)$ & $143(5.9)$ & \\
\hline Common mental disorder, $n$ (\%) & $1703(43.5)$ & $913(37.1)$ & $<0.001$ \\
\hline Fatigue $^{a}$ mean (s.d.) & $3.3(3.2)$ & $3.4(3.4)$ & 0.20 \\
\hline
\end{tabular}

\begin{tabular}{|c|c|c|c|c|c|c|c|c|}
\hline \multirow[b]{2}{*}{ Fatigue category } & \multicolumn{2}{|c|}{ Brazil } & \multicolumn{2}{|c|}{ UK } & \multirow{2}{*}{$\begin{array}{c}\text { Unadjusted } \\
\mathrm{OR}^{\mathrm{C}} \\
(95 \% \mathrm{Cl})\end{array}$} & \multirow{2}{*}{\multicolumn{2}{|c|}{$\begin{array}{c}\text { Adjusted } \\
\mathrm{OR}^{\mathrm{d}} \\
(95 \% \mathrm{Cl})\end{array}$}} & \multirow[b]{2}{*}{$P$} \\
\hline & $\begin{array}{c}\text { Total } \\
\text { screened }^{\mathrm{b}}\end{array}$ & $\begin{array}{c}\text { Prevalence } \\
n(\%)\end{array}$ & $\begin{array}{c}\text { Total } \\
\text { screened }^{\mathrm{b}}\end{array}$ & $\begin{array}{c}\text { Prevalence } \\
n(\%)\end{array}$ & & & & \\
\hline Unexplained chronic fatigue & 3914 & 476 (12.2) & 2459 & $253(10.3)$ & $0.83(0.70-0.97)$ & 0.02 & $0.92(0.74-1.13)$ & 0.42 \\
\hline Chronic fatigue syndrome & 3914 & $64(1.6)$ & 2459 & $51(2.1)$ & $1.27(0.88-1.85)$ & 0.20 & $1.52(0.94-2.44)$ & 0.09 \\
\hline Diagnostic labels & 391 & 0 & 269 & $11(4.1)$ & Not applicable & $<0.001^{\mathrm{e}}$ & Not applicable & $<0.001^{€}$ \\
\hline \multicolumn{9}{|c|}{$\begin{array}{l}\text { a. Diagnostic labels related to chronic fatigue syndrome included 'chronic fatigue', 'chronic fatigue syndrome', 'myalgic encephalomyelitis' and 'post-viral fatigue syndrome'. } \\
\text { b. For diagnostic labels, total is the number of medical notes reviewed. } \\
\text { c. Odds ratio calculated with Brazil as the reference category. } \\
\text { d. Adjusted for age, gender, education, marital status, employment status, occupation and common mental disorder. } \\
\text { e. P for chi-squared test. }\end{array}$} \\
\hline
\end{tabular}


status, employment status and occupation) and common mental disorder using multivariate logistic regression, the differences in the prevalence of unexplained chronic fatigue and chronic fatigue syndrome between the two groups were not statistically significant (Table 2).

In Brazil, of 609 individuals with chronic fatigue, we could only locate medical records for 391. Those for whom we could not locate medical records were less educated $(P<0.001)$ and more likely to have a manual occupation $(P<0.001)$, whereas all the other characteristics including fatigue level were similar. None of the 391 medical records reviewed $(0 \%, 95 \%$ CI $0-0.9)$ had any mention of chronic fatigue, chronic fatigue syndrome, myalgic encephalomyelitis or post-viral fatigue syndrome (Table 2 ). In the UK, we located medical records for 269 out of 305 individuals with chronic fatigue and 11 of the medical records reviewed $(4.1 \%, 95 \%$ CI $2.1-7.2)$ contained such a diagnosis $\left(\chi^{2}=16.26\right.$, d.f. $\left.=1, P<0.001\right)$. No logistic regression was conducted for this fatigue category due to a zero cell.

\section{Discussion}

Unexplained chronic fatigue was a common symptom with a comparable prevalence in both Brazilian and British primary care settings. As expected, chronic fatigue syndrome was less common than unexplained chronic fatigue, but prevalence was similar in both settings. Although both unexplained chronic fatigue and chronic fatigue syndrome were therefore similarly common in the two countries, Brazilian GPs were unlikely to recognise or diagnose chronic fatigue syndrome unlike their British colleagues, in accordance with the study hypothesis.

\section{Prevalence of unexplained chronic fatigue and chronic fatigue syndrome}

Our study used a design similar to those of previous British primary care studies, and the prevalence of unexplained chronic fatigue (12.2\% in Brazil and $10.3 \%$ in Britain) was roughly similar to previous estimates $\left(11.2 \%\right.$ by McDonald et $a^{26}$ and $11.3 \%$ by Wessely et $\left.\mathrm{al}^{23}\right)$. Chronic fatigue syndrome was also comparably prevalent (1.6\% in Brazil and $2.1 \%$ in Britain) to previous UK and USA estimates $\left(2.6 \%\right.$ by Wessely et $a^{23}$ and $2.5 \%$ by Reeves et $\left.a l^{20}\right)$. In the same way as fatigue is a universal symptom occurring across regions and cultures, chronic fatigue syndrome as defined by the current international consensus was also similar between Brazil and the UK. Furthermore, unexplained chronic fatigue as a less severe sub-syndromal counterpart of chronic fatigue syndrome was similarly common across the two countries, consistent with the notion that fatigue is distributed as a continuous variable in the general population. ${ }^{2,28}$

\section{Recognition and labelling of fatigue}

Terms such as chronic fatigue syndrome, myalgic encephalomyelitis and post-viral fatigue syndrome are routinely made diagnoses in British primary care as shown by the analysis of the UK General Practice Research Database. ${ }^{33}$ However, two vignette studies from Brazil showed that even university-based tertiary care doctors are unfamiliar with the construct of chronic fatigue syndrome and rarely diagnose it in their medical practice. ${ }^{12,34}$ Our study confirmed this observation using actual case notes. Although the prevalence of the syndrome in Brazil as assessed using a standardised procedure is comparable to that in the UK, it is not a diagnostic concept currently used in Brazilian medical practice and is neither recognised nor diagnosed.
Fatigue as a symptom elicited by a questionnaire or recorded by an interviewer should mostly reflect the presence or absence of the symptom in an individual. However, fatigue as a diagnosis made by the physician depends upon factors other than the simple presence or absence of the symptom. Much needs to happen for GPs to recognise fatigue cases and label them with such diagnoses as chronic fatigue syndrome, myalgic encephalomyelitis and postviral fatigue syndrome. First of all, the doctor needs to attribute some importance to the symptom of fatigue. It has been shown that doctors accord fatigue only a minor importance in comparison with patients - doctors rate it as far less important than patients, probably because of its ubiquity and lack of diagnostic specificity. ${ }^{35}$ Furthermore, the practitioner needs to be aware of these labels and to have at least some knowledge of the diagnostic concept. Even then, a practitioner may be well aware of the concepts and/or labels, but feel that these are not valid or useful, and hence not use them. Studies of doctors' knowledge and attitudes towards chronic fatigue syndrome/myalgic encephalomyelitis have indicated that opinions vary widely about the existence and utility of these labels. ${ }^{36,37}$ There are also changes in physicians' diagnostic patterns for fatigue over time. ${ }^{33}$

These factors, upon which the recognition and labelling of fatigue depend, may have an important link with the sociocultural setting. The degree of medicalisation of the population and awareness of chronic fatigue syndrome among the population and the medical professionals may be important. The explanatory models held by individuals with chronic fatigue seem to be more biomedically oriented in Western affluent societies compared with non-Western societies. ${ }^{38-40}$ Further data from the current study, reported elsewhere, ${ }^{41}$ demonstrated that British people with unexplained chronic fatigue were more likely to attribute their fatigue to physical causes than their Brazilian counterparts in line with this proposition. Moreover, while chronic fatigue syndrome is well known and officially endorsed as a medical condition in the $\mathrm{UK}^{42}$ it is little known in Brazil by either patients or doctors. ${ }^{12,34}$ We believe that these differences in sociocultural context between Brazil and the UK have contributed to the current findings. Conversely, these findings indicate the importance of sociocultural factors not so much in the occurrence and distribution of fatigue but more in the recognition and labelling of fatigue. In Brazil, where unexplained fatigue is not sanctioned as a medical condition worthy of medical treatment, sick leave or sickness benefit, ${ }^{12,34}$ it may be more likely to be considered as part of everyday adversity and less likely to be recognised as a medical disorder. Likewise, individuals with a similar range of symptoms are considerably less likely to receive a label of chronic fatigue syndrome/myalgic encephalomyelitis in Brazil than in the UK.

\section{Limitations and strengths}

The study has some limitations. First, the medical records review for the assessment of fatigue diagnosis was incomplete in Brazil medical records could not be traced for almost $30 \%$ of Brazilian participants with chronic fatigue. In addition, although the UK medical records were all electronic and mostly complete, the available Brazilian medical records were all on paper and frequently lacking information on examination results. None the less, the absence of any fatigue diagnosis in a far larger pool of medical records in Brazil is unlikely to be explained by this limitation. In addition, the type of quality problem observed in the Brazilian medical records was not directly related to diagnostic labels and we conducted laboratory tests in Brazil to compensate for this particular deficiency. Furthermore, as mentioned above, there is also evidence that Brazilian doctors are unfamiliar with the construct of chronic fatigue syndrome and rarely use this 
diagnosis in their practice. ${ }^{12,34}$ Second, general practices were not randomly selected and consequently selection bias was possible. In order to minimise this problem, we employed the sampling strategy of including different social classes in proportion to the national data and selecting general practices with similar characteristics in the two countries.

Despite these limitations, this study also had some strengths as it included large samples with a reasonable number of clinics; made a direct comparison of a poorly explored topic in two culturally and economically distinct settings using the same method; employed cross-culturally validated measures of fatigue and psychological distress; and conducted multivariable analyses.

This is the first study to specifically estimate the prevalence of unexplained chronic fatigue/chronic fatigue syndrome in Brazil. If taken at face value, it raises the question of unexplained chronic fatigue/chronic fatigue syndrome as a hidden public health issue in Brazil given the prevalence of and the disability caused by the conditions. More importantly, this is the first study to examine the epidemiology of chronic fatigue syndrome using the same standardised methodology across two culturally and economically distinct countries, an Anglophone affluent country and a Latin American middle-income country. Despite its limitations, this study provides some evidence about the role of sociocultural factors in the recognition of fatigue and the use of labels such as chronic fatigue syndrome/myalgic encephalomyelitis. In other words, the recognition of this illness rather than the illness itself seems to be culturally induced. The overall conclusion is that unexplained chronic fatigue/chronic fatigue syndrome can be found in Brazil in similar proportions as the UK, if one cares to look. At the moment, it seems that Brazilian society, or more specifically its healthcare system, does not care to look. How appropriate that is, and what the impact is, will remain a matter of speculation. Further research on the pragmatic implications of the current findings may shed more light on the understanding of this controversial, continuing but real health problem.

\footnotetext{
Hyong Jin Cho, MD, MSC, PhD, Department of Psychiatry, Federal University of São Paulo, Brazil, and Department of Psychological Medicine, Institute of Psychiatry, King's College London, UK; Paulo Rossi Menezes, MD, MSc, PhD, Department of Preventive Medicine, University of São Paulo Medical School, and Section of Epidemiology, University Hospital, University of São Paulo, Brazil; Matthew Hotopf BSC, MBBS, MRCPsych, MSC, PhD, Department of Psychological Medicine, Institute of Psychiatry, King's College London, UK; Dinesh Bhugra, MPhil, FRCPsych, PhD, Health Services Research Department, Institute of Psychiatry, King's College London, UK; Simon Wessely, MD, FRCPsych, Department of Psychological Medicine, Institute of
Simices Researi Psychiatry, King's College London, UK

Correspondence: H. J. Cho, Department of Psychiatry, Federal University of São Paulo, Rua Botucatu 740, CEP 04023-900, São Paulo, Brazil. Email:

h.cho@iop.kcl.ac.uk

First received 28 Feb 2008, final revision 17 Jul 2008, accepted 21 Aug 2008
}

\section{Acknowledgements}

This study was supported by grants from the Fundação Coordenação de Aperfeiçoamento de Pessoal de Nível Superior (CAPES), the Fundação de Apoio à Pesquisa no Estado de São Paulo (FAPESP proc. No. 04/02771-5), and the Institute of Social Psychiatry. P.R.M. was partly funded by the CNPq-Brazil. The University Hospital from the University of São Paulo allowed the infrastructure for the field work in Brazil. Professors Lawrence Kirmayer, Jair de Jesus Mari, Cecília Maria Sivalli Campos, and Ms Milena Oshiro are gratefully acknowledged for their valuable contribution to the study. The authors are also grateful to the doctors, staff and patients of the following general practices in São Paulo and London: UBAS-Hospital Universitário da Universidade de São Paulo (MS Ana Lúcia Mendes Lopes and Ms Marina Hideko Anabuki), UBS Nosa Senhora do Brasil (Dr Solange Consentino Munhoz), UBS Jardim Boa Vista (Dr Maria da Glória Pereira de Castro Casanova), UBS Cambuci (Dr Susana Gualda de Freitas Rodrigues), UBS São Jorge (Dr Mia Umeda), Selsdon Park Medical Practice (Dr Henk Parmentier and Ms Pat Davey), Surrey Docks Health Centre (Dr Noel Baxter), Parkside Medical Practice (Dr George Varughese) and Hambleden Clinic (Dr Patricia Critchley).

\section{References}

1 Kroenke K, Wood D, Mangelsdorff D, Meier N, Powell J. Chronic fatigue in primary care: prevalence, patient characteristics and outcome. JAMA 1988; 260: 929-34.

2 Pawlikowska T, Chalder T, Hirsch SR, Wallace P, Wright DJ, Wessely SC. Population based study of fatigue and psychological distress. BMJ 1994; $\mathbf{3 0 8}$ : 763-6.

3 Hickie I, Davenport T, Issakidis C, Andrews G. Neurasthenia: prevalence, disability and health care characteristics in the Australian community. $\mathrm{Br} J$ Psychiatry 2002; 181: 56-61.

4 Patel V, Kirkwood BR, Weiss H, Pednekar S, Fernandes J, Pereira B, Upadhye $\mathrm{M}$, Mabey D. Chronic fatigue in developing countries: population based survey of women in India. BMJ 2005; 330: 1190.

$5 \mathrm{Kim} \mathrm{CH}$, Shin $\mathrm{HC}$, Won $\mathrm{CW}$. Prevalence of chronic fatigue and chronic fatigue syndrome in Korea: community-based primary care study. J Korean Med Sci 2005; 20: 529-34.

6 Njoku MGC, Jason LA, Torres-Harding SR. The prevalence of chronic fatigue syndrome in Nigeria. J Health Psychol 2007; 12: 461-74.

7 Office of Population Censuses and Surveys. Morbidity Statistics from General Practice: Third National Morbidity Survey. Her Majesty's Stationery Office, 1985.

8 US Department of Health and Human Statistics. National Ambulatory Medical Care Survey, USA: 1975-1981 and 1985 Trends. Series 13, No 93. National Center for Health Statistics, 1988.

9 Mouterde O. Myalgic encephalomyelitis in children. Lancet 2001; 357: 562.

10 Abbey SE, Garfinkel PE. Neurasthenia and chronic fatigue syndrome: the role of culture in the making of a diagnosis. Am J Psychiatry 1991; 148: 1638-46.

11 Bass C. Does myalgic encephalomyelitis exist? Lancet 2001; 357: 1889.

12 Cho HJ, Menezes PR, Bhugra D, Wessely S. The awareness of chronic fatigue syndrome: a comparative study in Brazil and the United Kingdom. J Psychosom Res 2008; 64: 351-5.

13 Lloyd AR, Hickie I, Boughton CR, Spencer O, Wakefield D. Prevalence of chronic fatigue syndrome in an Australian population. Med J Aust 1990; 153: $522-8$.

14 Buchwald D, Umali $P$, Umali J, Kith P, PearIman T, Komaroff AL. Chronic fatigue and the chronic fatigue syndrome: prevalence in a Pacific Northwest health care system. Ann Intern Med 1995; 123: 81-8.

15 Lawrie SM, Pelosi AJ. Chronic fatigue syndrome in the community. Prevalence and associations. Br J Psychiatry 1995; 166: 793-7.

16 Reyes M, Gary HE Jr, Dobbins JG, Randall B, Steele L, Fukuda K, Holmes GP, Connell DG, Mawle AC, Schmid DS, Stewart JA, Schonberger LB, Gunn WJ, Reeves WC. Surveillance for chronic fatigue syndrome - four US cities, September 1989 through August 1993. MMWR CDC Surveill Summ 1997; 46: $1-13$.

17 Kawakami N, Iwata N, Fujihara S, Kitamura T. Prevalence of chronic fatigue syndrome in a community population in Japan. Tohoku J Exp Med 1998; 186: 33-41.

18 Jason LA, Richman JA, Rademaker AW, Jordan KM, Plioplys AV, Taylor RR, McCready W, Huang CF, Plioplys S. A community-based study of chronic fatigue syndrome. Arch Intern Med 1999; 159: 2129-37.

19 Reyes M, Nisenbaum R, Hoaglin DC, Unger ER, Emmons C, Randall B, Stewart JA, Abbey S, Jones JF, Gantz N, Minden S, Reeves WC. Prevalence and incidence of chronic fatigue syndrome in Wichita, Kansas. Arch Intern Med 2003; 163: 1530-6.

20 Reeves WC, Jones JF, Maloney E, Heim C, Hoaglin DC, Boneva RS, Morrissey $\mathrm{M}$, Devlin R. Prevalence of chronic fatigue syndrome in metropolitan, urban, and rural Georgia. Popul Health Metr 2007; 5: 5.

21 Bates DW, Schmitt W, Buchwald D, Ware NC, Lee J, Thoyer E, Kornish RJ, Komaroff AL. Prevalence of fatigue and chronic fatigue syndrome in a primary care practice. Arch Intern Med 1993; 153: 2759-65.

22 Versluis R, De Waal MWM, Opmeer C, Petri H, Springer M. Prevalence of chronic fatigue syndrome in four general practices in Leyden region [Dutch]. Ned Tijdschr Geneeskd 1997; 141: 1523-6.

23 Wessely S, Chalder T, Hirsch S, Wallace P, Wright D. The prevalence and morbidity of chronic fatigue and chronic fatigue syndrome: a prospective primary care study. Am J Public Health 1997; 87: 1449-55.

24 Bazelmans E, Vercoulen JH, Swanink CM, Fennis JF, Galama JM, van Weel C, van der Meer JW, Bleijenberg G. Chronic fatigue syndrome and primary fibromyalgia syndrome as recognized by GPS. Fam Pract 1999; 16: 602-4.

25 Sharpe M. ABC of psychological medicine: fatigue. BMJ 2002; 325: 480-3.

26 McDonald E, David AS, Pelosi AJ, Mann AH. Chronic fatigue in primary care attenders. Psychol Med 1993; 23: 987-98. 
27 David A, Pelosi A, McDonald E, Stephens D, Ledger D, Rathbone R, Mann A. Tired, weak, or in need of rest: fatigue among general practice attenders. BMJ 1990; 301: 1199-202.

28 Chalder T, Berelowitz G, Pawlikowska T, Watts L, Wessely S, Wright $D$, Wallace EP. Development of a fatigue scale. J Psychosom Res 1993; 37 : 147-53

29 Cho HJ, Costa E, Menezes PR, Chalder T, Bhugra D, Wessely S. Cross-cultural validation of the Chalder Fatigue Questionnaire in Brazilian primary care. J Psychosom Res 2007; 62: 301-4.

30 Fukuda K, Straus SE, Hickie I, Sharpe MC, Dobbins JG, Komaroff A. The chronic fatigue syndrome: a comprehensive approach to its definition and study. International Chronic Fatigue Syndrome Study Group. Ann Intern Med 1994; 121: 953-9.

31 Goldberg D, Williams P. A User's Guide to the General Health Questionnaire. National Foundation for Educational Research, 1991.

32 Mari JJ, Williams P. A comparison of the validity of two psychiatric screening questionnaires (GHQ-12 and SRQ-20) in Brazil, using Relative Operating Characteristic (ROC) analysis. Psychol Med 1985; 15: 651-9.

33 Gallagher AM, Thomas JM, Hamilton WT, White PD. Incidence of fatigue symptoms and diagnoses presenting in UK primary care from 1990 to 2001 J $R$ Soc Med 2004; 97: 571-5.

34 Nacul LC, Perreira FLR, Jacques GA, Ramos AG, Rodrigues CJA, Oliva IB, Gonçalves NR, Almeida RC. What do doctors and health workers of
Northeast Brazil know and do about chronic fatigue syndrome? J Chronic Fatigue Syndrome 1999; 5: 89-90.

35 Dohrenwend B, Crandell D. Psychiatric symptoms in community, clinic and mental hospital groups. Am J Psychiatry 1970; 126: 1611-21.

36 Bowen J, Pheby D, Charlett A, McNulty C. Chronic fatigue syndrome: a survey of GPS' attitudes and knowledge. Fam Pract 2005; 22: 389-93.

37 Finestone AJ. A doctor's dilemma. Is a diagnosis disabling or enabling? Arch Intern Med 1997: 157: 491-2.

38 Chalder T, Power MJ, Wessely S. Chronic fatigue in the community: 'a question of attribution'. Psychol Med 1996; 26: 791-800.

39 Lee S, Yu H, Wing Y, Chan C, Lee AM, Lee DT, Chen C, Lin K, Weiss MG. Psychiatric morbidity and illness experience of primary care patients with chronic fatigue in Hong Kong. Am J Psychiatry 2000; 157: 380-4.

40 Karasz A, McKinley PS. Cultural differences in conceptual models of everyday fatigue: a vignette study. J Health Psychol 2007; 12: 613-26.

41 Cho HJ, Bhugra D, Wessely S. 'Physical or psychological?' - a comparative study of causal attribution for chronic fatigue in Brazilian and British primary care patients. Acta Psychiatr Scand 2008; 118: 34-41.

42 Hutchinson A. A Report of the CFS/ME Working Group. Report to the Chief Medical Officer of an Independent Working Group. Department of Health, 2002. (http://www.dh.gov.uk/en/Publicationsandstatistics/ Publications/PublicationsPolicyAndGuidance/DH_4064840).

Reading works of fiction and attending to the language, the dialogue, the mood is like listening to patients. In both activities, we enter into other worlds, grasp something about the inner life of characters whose motivations may be unlike our own. D. H. Lawrence referring to this aspect of the novel wrote: 'It can inform and lead into new places the flow of our sympathetic consciousness, and it can lead our sympathy away in recoil from things gone dead. Therefore the novel, properly handled, can reveal the most secret places of life'. Is this not also, partly, the task of psychiatry?

Mindreadings: Literature and Psychiatry (ed. Femi Oyebode) has recently been published by RCPsych Publications. 